This is the peer reviewed version of the following article: Ith Ponndara, Dawson Angela, and Homer Caroline 2012, 'Quality of maternity care practices of skilled birth attendants in Cambodia', Wiley-Blackwell Publishing Asia, vol. 10, no. 1, pp. 60-67. which has been published in final form at http://dx.doi.org/10.1111/j.1744-1609.2012.00254.x This article may be used for non-commercial purposes in accordance With Wiley Terms and Conditions for self-archiving' 
Ith P, Dawson A, Homer CSE. (2012) Quality of Maternity Care Practices of Skilled Birth Attendants in Cambodia. International Journal of Evidence-Based Healthcare 10: 60-67.

\title{
Quality of Maternity Care Practices of Skilled Birth Attendants in Cambodia
}

\begin{abstract}
Background: The World Health Organization's recommended package of interventions for the integrated management of pregnancy and childbirth provides guidance for the use of evidencebased interventions to ensure the best outcomes for mother and newborn. However, the extent to which skilled birth attendants follow evidence-based guidelines is not known. There are few studies into childbirth practices of skilled birth attendants in Cambodia. The aim of this study was to observe practices of skilled birth attendants during labour, birth and the immediate postpartum period and their consistency with evidence-based guidelines.
\end{abstract}

Methods: A structured non-participant observation study was undertaken. Data were collected using an observational checklist of evidence-based practices adapted from the Cambodian clinical assessment tools for associate degree in midwifery. Maternity care settings in one provincial hospital, two district referral hospitals and two health centres in one province of Cambodia were purposively selected.

Results: Twenty five skilled birth attendants who attended 40 women during labour, birth and the postnatal period were observed. The results showed that the use of the partograph was low; birth companions were not permitted; cleanliness during birth was lacking; management of the third stage of labour was inappropriate; a lack of monitoring of mother and baby in the early postnatal period; the SBAs lacked skills in neonatal resuscitation; and skin to skin contact with the newborn and early breastfeeding was rare.

Conclusion: The findings suggest that the current SBA practices during labour, birth and the immediate postpartum period are not consistent with evidence-based guidelines. Service improvements which address evidence-based practices are likely to have an impact on clean and safe childbirth thereby enhancing outcomes for Cambodia women.

Key words: Cambodia, childbirth, evidence-based practice, labour practices, skilled birth attendant 


\section{Introduction}

Cambodia is a small country in South East Asia with a population of 14138 million. ${ }^{1}$ It is considered a middle income developing country. The maternal mortality rate in Cambodia has decreased from 580 per 100, 000 in 1999 to 290 per 100,000 live births in $2011 .{ }^{2}$ Nonetheless, Cambodia will not reach the United Nations 2015 MDG5 of a target 75\% reduction in the number of maternal deaths from 1990 levels. ${ }^{3}$ The major causes of maternal mortality in Cambodia, as in many similar countries $^{4,5}$ are abortion-related complications, obstructed labour, haemorrhage, eclampsia and infection. $^{6}$

Many developing countries, including Cambodia, have prioritized maternal health, focusing on increasing the number of births with a skilled birth attendant (SBA) in a health facility. ${ }^{7}$ SBAs have been widely advocated as an effective way to reduce maternal and perinatal morbidity and mortality in developing countries. ${ }^{8}$ WHO defines a skilled attendant as "an accredited health professional such as midwife, doctor or nurse who has been educated and trained to proficiency in the skills needed to manage normal (uncomplicated) pregnancies, childbirth and the immediate postnatal period, and in the identification, management and referral of complications in women and newborns". 9

In support of Safe Motherhood Initiatives and improving the skills of SBAs, the World Health Organization's recommended package of interventions for the integrated management of pregnancy and childbirth (IMPAC) provides evidence-based guidance to ensure the best outcomes 
for mother and newborn. ${ }^{10}$ In addition, countries including Cambodia have their own national guidelines that are tailored to the nation's unique context and health care system for midwives and doctors working in the health centres and hospitals. ${ }^{11,12}$ The National Guidelines outline the services, including maternal health care that should be provided at the various levels and are based on evidence. The minimum package of activities for health centres provides child immunization, antenatal care, normal delivery, neonatal care, breastfeeding, family planning, safe abortion, and refers complicated pregnancies to the hospital if necessary. ${ }^{11}$ The complementary package of activities for referral hospitals provides normal birth and basic and comprehensive emergency obstetric care. ${ }^{12}$ These packages of activities are informed by the WHO's IMPAC guidelines and other international evidence. ${ }^{13}$

Increasing women's access to quality maternity care services has become a focus of global efforts to realize the right of every woman to the best possible health care during pregnancy and childbirth. ${ }^{14,15}$ Maternal deaths or serious morbidity could be averted if women are able to access to a skilled attendant during birth and the early postpartum period, particularly when complications arise. ${ }^{16,17}$

However, problems of increasing women' s access to maternal care and services appear to be compounded by issues of competency ${ }^{15}$ and the perceived limited midwifery skills of SBAs. ${ }^{18}$ Competency is defined as possessing skills and knowledge sufficient to comply with predefined clinical standards. ${ }^{19}$ The recent State of the World's Midwifery Report highlights the need to have a sufficient workforce of well trained, accessible midwives to improve maternal health in developing countries. ${ }^{15}$ While addressing the need to train and deploy more midwives in a 
country is critical, strengthening the competency of the SBAs who currently provide care is also important. In addition, it is necessary to have a functioning health system that provides access to essential drugs, adequate equipment supplies and infrastructure that facilitates effective systems for communication referral and supervision which are required to maintain a motivated midwifery workforce to deliver life-saving interventions. ${ }^{15,20,21}$ Elements of the work environment, such as management, incentives and remuneration, education and training, regulatory frameworks and policies $^{9}$ have a severe negative impact on the recruitment and retention of health professionals, the productivity and performance of health facilities, and ultimately on the outcomes of women. The aspects, while important, are beyond the scope of this paper although it is recognised that ccompetencies of SBAs are one of the main barriers that affect service utilization and health outcomes $^{22}$ in countries like Cambodia.

Many women in developing countries experience serious barriers to accessing services. Women with severe complications may die because they delay seeking emergency obstetric care, or even if they arrive at a health facility in time, they may receive inadequate or inappropriate care. ${ }^{23,24}$ Studies have shown that practices that are not based on evidence or have unknown effectiveness have been used for decades, while those that potentially harm women and their infants continue to be used in many settings. ${ }^{25,26}$ For example, a study in Cameroon found that health workers providing reproductive health care were not aware of evidence-based interventions ${ }^{27}$ and a study in Jordan found a similar lack of evidence-based practices in maternity care. ${ }^{26} \mathrm{~A}$ national assessment by the Ministry of Health in Cambodia focused on the availability, quality and utilization of emergency obstetric and newborn care, but did not consider whether practices were based on evidence known to reduce maternal and perinatal morbidity and mortality. ${ }^{28,29}$ 
In Cambodia, only $44 \%$ of births are attended by trained skilled birth attendants (SBAs) ${ }^{2}$ and the extent to which SBA practice is evidence-based is unknown. In Cambodia, SBAs refers to primary and secondary midwives, nurse-midwives and doctors with midwifery who provide basic obstetric and emergency care in public health settings.

A primary midwife undergoes a one year-training program after completing secondary school education without necessarily attaining a year 12 grade (most applicants have only completed grade 7 schooling). The one-year Primary Midwifery program was introduced in rural Cambodia in 2003 in response to the severe shortage of midwives, and expanded nationwide in $2005 .{ }^{30} \mathrm{~A}$ secondary midwife completes a four-year training program. Although primary and secondary midwives work at all level of health care system, the intention was that primary midwives would work at health centres in a supportive role to secondary midwives. ${ }^{30}$

Medical doctors undertake an eight-year program with additional 6, 12 or 18 months to be specialist medical practitioners and three years to major in a specialty. ${ }^{31,32}$ These specialties include basic emergency obstetric and newborn care and general surgery. Doctors who received 612 month training programs were accredited as 'doctors with midwifery skills' while those who had 18 month training were considered as a general surgeon.

The practices of primary midwives and secondary midwives differ according to the national guidelines. ${ }^{12,33}$ For instance, secondary midwives who work in health centres can perform normal births but are not authorised to treat complications or use vacuum extraction or forceps to assist 
births and have to refer women with complications to the referral hospital. However, secondary midwives who work at the hospital level are authorised to manage women with complications who are referred from lower-level peripheral health centres.

The practice of SBAs directly impacts upon the quality of care patients receive, ${ }^{34}$ and the economic burden of unsafe care including prolonged hospitalization, loss of income, disability and litigation is compelling. ${ }^{35}$ Therefore, information about practice in relation to evidence-based standards is critical for quality improvement and cost effectiveness. In Cambodia, as in other developing nations SBA practice must be considered in relation to limited infrastructure, technology and resources. The aim of this study was to observe the SBAs practice during labour, birth and the immediate postpartum period and their consistency with evidence-based practice.

\section{METHODS}

An observational study was undertaken from December 2009 to March 2010. Non-participant observation was used as it enabled the researcher to observe what people actually do, as opposed to what they think they do, or would like others to think they do. Approval for this research project was granted by Human Research Ethics Committees (HREC) of the University of New South Wales and the National Ethics Committee for Health Research of the Cambodian Ministry of Health.

The study was undertaken in one province of Cambodia in maternity units in a range of public settings, including one provincial hospital, two district referral hospitals and two health centres. These health facilities were purposively selected as they represent the range of basic and 
comprehensive emergency obstetric care in the province. The province in which the study was undertaken was selected as it is well known to the first author who had established access to key participants. The name of this province, however, has not been disclosed due to the sensitive nature of the topic of the study and the need for confidentiality.

Participants consisted of a sample of primary and secondary midwives, nurses and doctors with midwifery skills, who attended births during the observation period. The Director of the Provincial Health Department wrote to hospitals and health centres, informing SBAs of the study and inviting them to participate in the study. SBAs who volunteered to participate were contacted by a senior SBA who could explain the study in detail and provide consent forms. In total, 25 SBAs agreed to participate in the study.

The participating SBAs were given verbal and written information about the criteria for women. Women who accessed the participating health facilities for labour and birth were approached by the SBAs on their arrival. The SBAs informed the women, both verbally and in writing, about the study in order to seek their permission to allow the researcher to be present in the birthing unit. Written informed consent in Khmer was obtained from 40 women who volunteered to be observed by the researcher. All participants were assured that they had the right to withdraw from the study at any point of the study. It was explained to the women that their participation in this study or refusal to participate would not affect their treatment or access to maternity or other health services. None of the participants refused to participate or withdraw from the study. 
Data were collected using an observation checklist based on the national clinical assessment tools for the associate degree in midwifery developed by the Cambodian Ministry of Health and UNFPA. ${ }^{13}$ The clinical assessment tool assesses the skills required to manage normal pregnancies, labour, birth and the immediate postpartum period and the identification, management and referral of complications of mothers and newborn babies as per the minimum and complementary packages of activities at health centres and referral hospitals. ${ }^{11,12}$

The clinical assessment tools consist of 60 steps for normal birth ${ }^{13}$ which although comprehensive, was beyond the scope of this study due to time restrictions. The 60 steps were summarized and focused on four key areas and 23 SBA activities as outlined in (Table 2). The observation of maternal problems in the first 24 hours after birth was added as a key area of focus as complications occur in approximately $15 \%$ of pregnancies and cannot be predicted. ${ }^{36}$ Death (due to postpartum haemorrhage) and referral to other level of care were included as two checklist items under this area. The administration of vitamin $\mathrm{K}$ was also included in the checklist under newborn practices to explore the application of this practice which although part of routine and standard care in developed countries ${ }^{37}$ is not well documented in Cambodia.

The observations were undertaken by the first author over two weeks at each of the health facilities. The first author is a medical doctor and a general surgeon who had received training in qualitative research methods, particularly observational research prior to data collection. Individual SBAs as well as teams of SBAs were observed over 24 hour periods. The observation checklists were used as a guide to observe SBA practice and completed outside the birthing room 
to help reduce the impact on the participants, both SBAs and women. The data were entered into an Excel spreadsheet and analysed using descriptive statistics.

\section{FINDINGS}

Twenty five skilled birth attendants who attended the labour and births of 40 women in the provincial hospital, two district referral hospitals and two health centres were observed. The SBAs included primary and secondary midwives, primary nurse-midwives and doctors with midwifery skills. The average age of SBAs was 44 years and most had more than 10 year experience in midwifery practice, except two primary midwives who had recently graduated.

All the women whose labour and births were observed were married. Only 25 (63\%) women had primary school education and only one woman had secondary school education. The majority of women $(88 \%)$ described themselves as housewives with only five $(12 \%)$ reporting working in paid employment outside the home. More than $70 \%$ of women were primiparous and almost twothirds of women had attended antenatal visit at the health centres during pregnancy (Table 1).

\section{Labour and birth practices}

All the observed women were asked about their general health condition and wellbeing and their history of antenatal care on admission. All SBAs performed a vaginal examination on women's admission to maternity ward and this was repeated less than every four hours. Only a quarter of women were monitored using the partograph even though partograph sheets were available at each of the health facilities. Various reasons were identified for this lack of usage including it not being part of the SBAs usual routine, heavy workload and time constraints (Table 2). 
All births were conducted without hand washing before gloving although water, soap and sink were available in the labour wards. Family members were allowed to support women in labour while they were moving around in the early stages of labour, but almost all (95\%) of them were not permitted to be present in during the birth. Only two women were able to have a family member with them during the birth. Most SBAs indicated that they could not deliver a baby in the presence of birth companions as they believed companions would affect the woman's compliance with SBA instructions. The risk of infection and disruption to the labour ward area were also reported as reasons for disallowing support in labour.

There were 38 vaginal births and two caesarean sections in the women observed. Episiotomy was routinely performed regardless of women's parity with 34 of the 38 women who had a vaginal birth having this procedure. SBAs indicated that episiotomies were important to avoid perineal trauma and tears which were more difficult to suture. They also believed that episiotomies would speed up the birth, a situation which was desirable given the high number of women in the labour wards.

Active management of the third stage of labour (AMTSL) was another aspect observed in the intrapartum care. It was observed that AMTSL was correctly performed in only five of the 38 vaginal births. There were wide variations of timing of oxytocin administration after the birth of the baby and fundal massage after the delivery of the placenta was missing. 
After the delivery of the placenta, all SBAs examined the placenta for completeness and abnormalities. Even if the placenta was intact and normal, 35 women (88\%) had a manual exploration and evacuation of the uterine cavity without anaesthetic performed by the SBA. SBAs indicated that this procedure was an appropriate way to avoid postnatal complications, including retained placenta and subsequent postpartum haemorrhage (Table 2).

\section{Postpartum practices}

The majority of women (85\%) observed were kept in the birth room for at least two hours after the immediate birth of the baby, but only five women (12\%) were regularly monitored and checked. It was observed that in health facilities which were short of SBAs, postnatal care was strongly affected by other duties. It was observed that after completing a birth, the SBA would rush off to undertake another activity or to care for other women leaving the woman alone.

Most women (83\%) did not experience an immediate complication although there were two maternal deaths in the 40 women observed. Four women who had a normal vaginal birth experienced a postpartum haemorrhage within 24 hours. Two of these women died as a result of the haemorrhage. While the complications of postpartum haemorrhage were detected by the SBAs, there was little support by the health system to assist the effective management of these emergency situations including a lack of blood and poor access to transportation for referral. Two women required a subtotal hysterectomy after their postpartum haemorrhage. Three other women had severe eclampsia, requiring transfer to a higher level of care (Table 2).

\section{Newborn practices}


Babies were not born onto a clean surface. Some of them were put on the floor near the birth table or onto a dirty weighing scale. The majority of babies (87\%) were not put in skin to skin contact with their mother and only one baby was given to his mother within half an hour of birth. Babies were left alone on a nearby table or given to family members outside the delivery room. In addition, only two women (5\%) started to breastfeed their babies within an hour.

The Apgar score was not commonly measured with only five babies having this assessment undertaken. SBAs did not monitor the baby in the first hour of labour; some SBAs did not notice newborn babies who cried after immediate birth, but within three minutes stopped breathing and became cyanotic. When family members reported the respiratory problems of one baby, the SBAs rushed to see the baby and sucked the secretion from their mouths and tapped the baby on the back. When the baby's condition deteriorated, SBAs gave inhalation with oxygen and left the room without doing anything else. SBAs did not explain or provide any information regarding the status of the baby to the family members, but referred them on to tertiary care. One SBA indicated that this was the best she could do in the situation. She said that the doctors did not have the skills and experiences to help the baby.

Clean cord care is another element of newborn care. In four births, the umbilical cords were tied with unsterile thread. All babies had an antiseptic solution (betadine) applied to their cord stump which was then covered with gauze. The administration of antimicrobial eye drops, such as tetracycline $1 \%$ ointment or chloramphenicol solution to the eye of the baby was common occurring in 14 (35\%) babies. One quarter of babies were given intramuscular injection of vitamin $\mathrm{K}$ to prevent haemorrahgic disease of the newborn (Table 2 ). 


\section{DISCUSSION}

The findings of this study show that the current childbirth practices of SBAs are not consistent with evidence-based practices. Appropriate and adequate care was often not provided and could have contributed to harm. These findings are similar to other studies across developing countries, which show a high level of harmful practices for low-risk women. ${ }^{26,38}$

Evidence of hand hygiene was limited in this study. Hand-washing practices during birth and in preparation for birth were not widely practised or adopted as part of normal routine care. Poor compliance with hand hygiene by heath staff is one of the underlying sources of health careassociated infections. ${ }^{39}$ The World Health Organization promotes the practice of 'six cleans' during birth. ${ }^{40}$ These include clean hands of the birth attendants, clean delivery surface, clean perineum of the mother, clean cord cutting instrument, clean cord clamping instrument and clean cord care. In settings in which the majority of births are conducted in the home and/or under unhygienic conditions, clean delivery kits, a pre-packaged, single-use, disposable kits containing soap, a plastic sheet, a blade, and sterilized thread for conducting clean birth are invaluable. However, while births are conducted in a health facility where hygiene can be better managed, SBAs underestimated their patient contacts and the risk they pose to mothers and newborns from the spread of infections. The finding showed that despite formal pre-service education and in-service training concerning clean and safe delivery and the availability of sink, water and soap, compliance with hand washing and barrier precautions is unacceptable poor practice reflecting similar

challenges in all health care settings. ${ }^{41}$ The lack of proper hand hygiene among skilled birth attendants may be explained by the lack of knowledge of basic hygiene practices and 
understanding of the relevant WHO Guidelines on standard precautions and cleanliness, especially hand hygiene in health care. ${ }^{10}$ In Cambodia, patients would not demand that their midwives or doctors wash their hands before they touch them or prepare to attend them during birth, as they felt that it could affect their future treatment and care. Dissemination of infection prevention information and health education messages at the community level and in health facilities focusing on clean and safe birth practices are essential to raise the hygiene awareness of women and their families. Such health education would enable women and their families to advocate for hand hygiene and help to change SBA practice.

There is strong evidence that the presence of companions of the woman's choice during labour and birth has a positive influence on women satisfaction and great benefits with the birth process. ${ }^{42,43}$ However, almost all SBAs in this study did not allow such support to be provided. This finding is similar to a study in Jordan, where the lay-out of the labour wards and limited knowledge of family members about childbirth prevented support in labour. ${ }^{26}$ The lack of support in labour constitutes a challenging barrier to increasing skilled care utilization and improving maternal health outcomes as women, especially the poor and marginalized, will continue to seek traditional birth attendants in preference as they can provide social and cultural knowledge, consolation, empathy and psychosocial support at birth that has important benefits for mothers and their babies. ${ }^{44,45}$

Cambodia has prioritized increasing the proportion of births attended by a SBA to enhance the quality of care during childbirth in health facilities and reduce maternal mortality. One of the challenges in this respect was the quality of obstetric practice, including limited use of the 
partogram for monitoring the progress of labour and inappropriate management of the third stage of labour. The partogram is an inexpensive tool that assists health workers in identification of concerns and early decision-making in relation to consultation, augmentation of labour, and possible transfer or caesarean section to ensure positive birth outcomes. Lower cadres of various primary health care workers can be effectively be trained to use the partogragh with satisfactory results highlighting the utility of the tool. ${ }^{46}$ The proportion of SBAs and facilities using partogram is low, as shown in other studies. ${ }^{30,47}$ It is therefore important that policy makers and to ensure that all SBAs receive this training or are motivated to use the partograph for all laboring women.

Postpartum haemorrhage (PPH) is one of the leading causes of maternal death, accounting for at least half the maternal mortality in Cambodia ${ }^{4,6}$ which is similar to other countries. ${ }^{48}$ The World Health Organization, the International Federation of Gynaecologists and Obstetricians and the International Confederations of Midwives recommend on use of AMTSL to PPH. ${ }^{49}$ The majority of SBAs in our study were aware of the components of AMTSL, but their practices did not comply with the elements of AMTSL, which is an area of significant concern with maternal mortality. These findings are supported by other observation studies, ${ }^{47,50,51}$ as well as a survey study in Nigeria. ${ }^{52}$

The SBAs in this study lacked confidence in their skills to assess newborn babies and often failed to recognize the need for resuscitation when a baby had respiratory problems. The provision of basic neonatal resuscitation could avert 30 percent of intra-partum related neonatal deaths, as well as $5-10 \%$ of deaths due to preterm birth $^{53,54}$ and success is possible in low-income countries even without highly developed technology. ${ }^{55}$ These practices include maintaining warmth of the baby, 
early and frequent breastfeeding, keeping the baby and mother together, ensuring hygiene and the prompt recognition and treatment of illness. While newborn babies were born in institutions, SBAs did not display or use basic resuscitation skills which are simple and necessary to save the life of the baby because very few babies need advanced resuscitation such as endotracheal intubation and drug and these newborn babies may not survive without continual ventilation. ${ }^{53}$ Advanced neonatal resuscitation is not a priority in settings without neonatal intensive care ${ }^{53}$ and the perception of the need for specialist skills in neonatal resuscitation may be the result of a lack of knowledge of relevant clinical protocols, adequate training and mentoring and teamwork. Only 14 (35\%) of the babies were given antimicrobial eye drops and a quarter were administered vitamin K. Evidence suggested that haemorrhagic disease of the newborn can occur when prophylactic vitamin $\mathrm{K}$ is not administered and that it can have devastating consequences. ${ }^{37}$ The routine intramuscular injection of vitamin $\mathrm{K}$ to all infants should be standardized in the national guidelines as well as the clinical assessment tools, which are key steps to improve newborn health.

Cambodia has made significant progress to reduce deaths in children under five ${ }^{56}$, but newborn babies have been largely unnoticed or un-reported. The neonatal mortality rate in Cambodia has been estimated to be 30 per 1000 live births. ${ }^{15}$ The lack of competency and experience of SBAs in assessing and recognizing the need for newborn resuscitation for births in health facilities could lead to a higher incidence of newborn with severe disability or chronic illness or even death. This study also showed that postnatal monitoring of newborn is not widely performed. Essential newborn care should be integrated into pre-service education and in-service trainings and handson practice provided so that skills are maintained and continuously upgraded. 
Limited monitoring of women in the early postnatal period occurred meant women were frequently left alone. This could lead to a lack of confidence in the institutional care provided at the health facilities. It is likely that many women would prefer support in the early postnatal period. This lack of monitoring also meant that complications, for example postpartum haemorrhage, were left undetected and contributed to morbidity and mortality.

This study had a number of limitations that may affect the generalisability of the results. The study was conducted in primarily provincial and district health centres and hospitals settings due to convenience and access to participants which means that specific issues relevant to urban public hospitals were not observed. These public health facilities were purposively selected and observations begun only after women were admitted in labour. The findings were based on the direct clinical observation of SBAs and self-report by a single researcher which although limited in breadth across Cambodia maternal settings ensures minimal variability in the study context. Many factors may have affected the performance of SBAs. For instance, SBAs who were nurses or midwives may have practised differently because of the presence of the researcher who was also a medical doctor. Furthermore, without essential drugs, equipment or supplies, a highly competent provider might perform poorly. With competent assistants and all necessities at hand, a marginal provider might perform well but perhaps the SBAs in this study did not have this opportunity. ${ }^{47}$ The strengths of this study lies in the rich and comprehensive descriptive data produced from observation of actual clinical practices of SBAs. As a result, the findings may be relevant to other contexts of SBA practice in Cambodia and other developing country contexts. 


\section{CONCLUSION}

Childbirth practices of SBAs during labour, birth and the immediate postnatal periods in one province of Cambodia are not always consistent with best practice and evidence. Education and quality improvement system that health service should engage in is to ensure that harmful practices are unaccepted and evidence-based practices are implemented to improve maternal health and accelerate progress towards the United Nations 2015 MDG5 target of a 75\% reduction in the number of maternal deaths. Future research is needed to examine why these evidencebased practices are not being implemented in Cambodia. 


\section{REFERENCES}

1 United Nations Department of Economics and Social Affairs. Population Division of the Department of Economic and Social Affairs of the United Nations Secretariat, World Population Prospects: The 2010 Revision. Accessed 06 Octobre 2011. Available from: http://esa.un.org/unpd/wpp/index.htm.

$2 \quad$ World Health Organization. World Health Statistics. 2011.

3 Countdown Coverage Writing Group. Countdown to 2015 for maternal, newborn, and child survival: the 2008 report on tracking coverage of interventions. Lancet. 2008; 371:1247-58.

$4 \quad$ AbouZahr C. Global burden of maternal death and disability. Br Med Bull. 2003; 67:1.

5 De Bernis L, Sherratt DR, AbouZahr C, Van Lerberghe W. Skilled attendants for pregnancy, childbirth and postnatal care. Br Med Bull. 2003; 67:39-57.

6 Ministry of Health Cambodia. Maternal death audit data from 10 provinces obtained from January 2005 to December 2006. Cambodia : MoH 2006. 2006.

7 Ministry of Health Cambodia. National Strategy for Reproductive and Sexual Health in Cambodia 2006-2010. 2006.

8 WHO. Reduction of Maternal Mortality: A joint WHO/UNFPA/UNICEF/World Bank statement.Geneva: Author. 1999.

9 World Health Organization. Making pregnancy safer: the critical role of the skilled attendant. Geneva 2004.

10 World Health Organization. Pregnancy, Childbirth, Postpartum and Newborn Care: A guide for essential practice. WHO Department of Making Pregnancy safer 2006.

11 Ministry of Health Cambodia. National guidelines for minimum package of activities for the development of the health centre 2008-2015. Phnom Penh: Ministry of Health, Cambodia. 2007.

12 Ministry of Health Cambodia. National guidelines for complementary package of activities for development of referral hospital 2006-2010. Phnom Penh: Ministry of Health, Cambodia. 2006.

13 Ministry of Health Cambodia. Clinical assessment tools for associate degree in midwifery. In: Department of Human Reources, ed. Phnom Penh, Cambodia 2009.

14 Adegoke AA, van den Broek N. Skilled birth attendance-lessons learnt. BJOG: An International Journal of Obstetrics \& Gynaecology. 2009; 116:33-40.

15 UNFPA. The State of the World's Midwifery 2011: Delivering Health, Saving Lives. 2011.

16 Family and Community Health. Global Action for Skilled Attendants for Pregnant Women Family and Community Health Department of Reproductive Health and Research; 2002.

17 World Health Organization. The World Health Report 2005: make every mother and child count.: Geneva, Switzerland:WHO; 2005.

18 Matsuoka S, Aiga H, Rasmey LC, Rathavy T, Okitsu A. Perceived barriers to utilization of maternal health services in rural Cambodia. Health Policy. 2010; 95:255-63.

19 Kak N, Burkhalter B, Cooper M-A. Measuring the competence of healthcare providers. The Quality Assurance Project: Bethesda, MD;. 2001.

20 Graham WJ, Bell JS, Bullough CH. Can skilled attendance at delivery reduce maternal mortality in developing countries ? Safe Motherhood Strategies : a Review of the Evidence by De Brouwere, Vincent and Lerberghe, Wim Van 2001. 
21 Bell J, Hussein J, Jentsch B, Scotland G, Bullough C, Graham W. Improving Skilled Attendance at Delivery: A Preliminary Report of the SAFE Strategy Development Tool. Birth. 2003; 30:227-34.

22 ten Hoope-Bender P, Campbell J, Fauveau V, Matthews Z. The state of the world's midwifery 2011: Delivering health, saving lives. International Journal of Gynecology \& Obstetrics. 2011; 114:211-2.

23 Gabrysch S, Campbell O. Still too far to walk: Literature review of the determinants of delivery service use. BMC Pregnancy and Childbirth. 2009; 9:34.

24 Ronsmans C, Graham W. Maternal Mortality: Who, When, Where, and Why. Maternal survival 1. 2006; 368:1189-2000.

25 World Health Organization. Care in Normal Birth: A Practical Guide. Report of a Technical Working Group. WHO: Geneva.; 1999.

26 Shaban IA, Hatamleh R, Khresh R, Homer C. Childbirth practices in Jordanian public hospitals: consistency with evidenc-based maternity care? . International Journal of Evidence-Based Healthcare. 2011.

27 Tita ATN, Selwyn BJ, Waller DK, Kapadia AS, Dongmo S. Evidence-based reproductive health care in Cameroon: population-based study of awareness, use and barriers. Bulletin of the World Health Organization. 2005; 83:895-A.

28 Ministry of Health. Cambodia EmONC Improvement Plan for Implementation January 2010 - December 2015. 2009.

29 Ministry of Health. National Emergency Obstetrics and Neonatal Care Assessment in Camobodia In: Ministry of Health Cambodia, ed. Phnom Penh 2009.

30 Sheratt DR, White P, Chhuong CK. Report of Comprehensive Midwifery Review,. Final Report: Ministry of Health of Cambodia 2006.

31 Ministry of Health. Overview of Pre-Service Education for Health in Cambodia. In: Department of Human Reources, ed. 2010.

32 Ministry of Health. Health Workforce Development Plan. In: Human Resource Development Department, ed. Phnom Penh: Ministry of Health, Cambodia 2006.

33 Ministry of Health Cambodia. National guidelines for minumum package of activities for development of the health centre 2008-2015. Phnom Penh: Ministry of Health, Cambodia. 2007.

34 Smith H, Brown H, Hofmeyr GJ, Garner P. Evidence-based obstetric care in South Africa influencing practice through the 'Better Births Initiative'. SAMJ. 2004; 94.

35 Kohn LT, Corrigan JM, Donaldson MS. To Err Is Human: Building a Safer Health System. NATIONAL ACADEMY PRESS Washington, D.C: INSTITUTE OF MEDICINE 1999.

36 Say L, Pattinson R, Gulmezoglu AM. WHO systematic review of maternal morbidity and mortality: the prevalence of severe acute maternal morbidity (near miss). Reproductive Health. 2004; 1:3.

37 Hubbard D, Tobias JD. Intracerebral Hemorrhage due to Hemorrhagic Disease of the Newborn and Failure to Administer Vitamin K at Birth. Southern Medical Journal. 2006; 99:1216-20.

38 Buekens P. Over-medicalisation of Maternal Care in Developing Countries. Safe Motherhood Strategies :a Review of the Evidence Vincent De Brouwere and Wim Van Lerberghe. 2001.

39 Pittet D, Donaldson SL. Clean Care is Safer Care: The First Global Challenge of the WHO World Alliance for Patient Safety. Infection Control and Hospital Epidemiology. 2005; 26. 
40 WHO UNFPA UNICEF World Bank. IMPAC-managing complications in pregnancy and childbirth: a guide for midwives and doctors. WHO, Department of Reproductive Health and Research: Geneva; 2003. Vol WHO/RHR/00.7 2003.

41 Pittet D. Improving Adherence to Hand Hygiene Practice: A Multidisciplinary Approach. Emerging Infectious Diseases. 2001; 7:234.

42 Bruggemann O, Parpinelli M, Osis M, Cecatti J, Neto A. Support to woman by a companion of her choice during childbirth: a randomized controlled trial. Reproductive Health. 2007; 4:5.

43 Hodnett E, Gates S, Hofmeyr G, Sakala C. Continuous support for women during childbirth Cochrane Database Systematic Review 2007;(3): artNo:CD 003766. 2007.

44 Bergström S, Goodburn E. The role of traditional birth attendants in the reduction of maternal mortality. Studies in Health Services Organization and Policy. 2001.

45 Costello A, Azad K, Barnett S. An alternative strategy to reduce maternal mortality. Lancet. 2006; 06:69388-4.

46 Fatusi AO, Makinde ON, Adeyemi AB, Orji EO, Onwudiegwu U. Evaluation of health workers' training in use of the partogram. International Journal of Gynecology \&amp; Obstetrics. 2008; 100:41-4.

47 Harvey SA, Blandón YCW, McCaw-Binns A et al. Are Skilled Birth Attendants Really Skilled? A Measurement Method, Some Disturbing Results and a Potential Way Forward. Bulletin of the World Health Report. 2007; 85:11.

48 Kongnyuy EJ, Mlava G, Van Den Broek N. Facility-based maternal death review in three districts in the central region of Malawi: an analysis of causes and characteristics of maternal deaths. Women's Health Issues. 2009; 19:14-20.

49 Lalonde A, Daviss BA, Acosta A, Herschderfer K. Postpartum hemorrhage today: ICM/FIGO initiative 2004-2006. International Journal of Gynecology \& Obstetrics. 2006; 94:243-53.

50 Liljestrand J, Rathavy T, Moore J. Critical Components of Skilled Birthing Care in Cambodia: Active Management of the Third Stage of Labor (AMTSL ) and Management of Eclampsia. 2009.

51 Stanton C, Armbruster D, Knight R et al. Use of active management of the third stage of labour in seven developing countries. Bulletin of the World Health Organization. 2009; 87:207-15.

52 Oladapo OT, Fawole AO, Loto OM et al. Active management of third stage of labour: a survey of providers' knowledge in southwest Nigeria. Archives of gynecology and obstetrics. 2009; 280:945-52.

53 Wall SN, Lee ACC, Niermeyer S et al. Neonatal resuscitation in low-resource settings: What, who, and how to overcome challenges to scale up? International Journal of Gynecology \& Obstetrics. 2009; 107:S47-S64.

54 Andersson T, Högberg U, Bergström S. Community-based prevention of perinatal deaths: lessons from nineteenth-century Sweden. International Journal of Epidemiology. 2000; 29:542-8.

55 Martines J, Paul VK, Bhutta ZA et al. Neonatal survival: a call for action. Lancet. 2005; 365:1189-97.

56 NIPH, NIS. Cambodia Demographic and Health Survey 2005. National Institute of Public Health (NIPH) and National Institute of Statistics (NIS),ORC Macro 2006. 
Table 1: Demographic characteristics of the women who were observed

\begin{tabular}{|c|c|c|}
\hline Variable & Frequency $(n=40)$ & Percentage (100\%) \\
\hline \multicolumn{3}{|l|}{ Marital status } \\
\hline - Married & 40 & 100 \\
\hline \multicolumn{3}{|l|}{ Employment status } \\
\hline - Farmer/housewife & 35 & 88 \\
\hline - $\quad$ Paid job & 5 & 12 \\
\hline \multicolumn{3}{|l|}{ Education level } \\
\hline - Illiterate & 14 & 35 \\
\hline - Primary school & 25 & 63 \\
\hline - Secondary school & 1 & 3 \\
\hline \multicolumn{3}{|l|}{ Parity } \\
\hline - Primiparous & 29 & 73 \\
\hline - Multiparous & 11 & 28 \\
\hline \multicolumn{3}{|c|}{ Had antenatal care this pregnancy } \\
\hline - Yes & 26 & 65 \\
\hline - No & 15 & 35 \\
\hline \multicolumn{3}{|l|}{ Problems during pregnancy } \\
\hline - Bleeding & 5 & 13 \\
\hline - Eclampsia & 3 & 8 \\
\hline
\end{tabular}


Table 2 Frequency and proportions of practices in the women who were observed

\begin{tabular}{|c|c|c|}
\hline Activities performed by SBAs & $\begin{array}{l}\text { Frequency } \\
(n=40)\end{array}$ & $\begin{array}{l}\text { Percentage } \\
(100 \%)\end{array}$ \\
\hline \multicolumn{3}{|l|}{ Labour and birth practices } \\
\hline - Ask the history of the woman & 40 & 100 \\
\hline - Use of partograph to monitor progress of labour & 10 & 25 \\
\hline $\begin{array}{l}\text { - Hand-washing/hands rubbing (with soap and plain water or } \\
\text { antiseptic) }\end{array}$ & 0 & 0 \\
\hline - Vaginal examination less than every 4hours & 40 & 100 \\
\hline - Monitoring of fetal heart rate & 0 & 0 \\
\hline \multicolumn{3}{|l|}{ Care during labour and childbirth } \\
\hline - Birth companion was permitted to attend labour & 2 & 5 \\
\hline - Clean delivery surface & 0 & 0 \\
\hline - Episiotomy & 34 & 85 \\
\hline - Vacuum extraction & 5 & 13 \\
\hline - $\quad$ Correct use of AMTSL & 5 & 13 \\
\hline $\begin{array}{l}\text { - Examine the placenta and membranes for completeness and } \\
\text { abnormalities }\end{array}$ & 40 & 100 \\
\hline - Manual exploration/evacuation of uterine cavity & 35 & 88 \\
\hline - C-sections (plus subtotal hysterectomy) & 2 & 5 \\
\hline \multicolumn{3}{|l|}{ Postpartum practices } \\
\hline \multicolumn{3}{|l|}{ - Follow-up and care of mother after birth } \\
\hline - Keep women 2 hours in the delivery room for follow-up & 34 & 85 \\
\hline $\begin{array}{l}\text { - Monitoring of vital signs and amount of external blood loss } \\
\text { within the first } 2 \text { hours after birth }\end{array}$ & 5 & 13 \\
\hline \multicolumn{3}{|l|}{ Newborn practices } \\
\hline \multicolumn{3}{|l|}{ - Immediate care of newborn (within 1 hours } \\
\hline - Assess Apgar Scores & 5 & 13 \\
\hline - Clean cord care (including cord ties and cutting surface) & 35 & 84 \\
\hline - Apply antimicrobial eye drops or ointment & 14 & 35 \\
\hline - Administration of vitamin $\mathrm{K}$ & 10 & 25 \\
\hline - Place the baby in skin-to- skin contact & 5 & 13 \\
\hline - Baby given to mother within half an hour & 1 & 3 \\
\hline - Early breastfeeding & 2 & 5 \\
\hline Maternal problems in the first $24 \mathrm{~h}$ after birth & 7 & 18 \\
\hline - Death (due to postpartum hemorrhage) & 2 & 5 \\
\hline - Referral to other level of care & 3 & 8 \\
\hline
\end{tabular}

